\title{
Computer application for railway track realignment
}

\author{
Michał Bednarczyk ${ }^{\mathrm{a}}$, Artur Janowski ${ }^{\mathrm{b}}$ \\ ${ }^{a}$ Department of Land Surveying and Geomatics, Faculty of Geodesy and Land Management, University of Warmia and Mazury in Olsztyn \\ ul. Heweliusza 12 (bl. 52), 10-724 Olsztyn, Poland \\ ${ }^{b}$ Institute of Geodesy, Faculty of Geodesy and Land Management, University of Warmia and Mazury in Olsztyn \\ ul. Oczapowskiego 1, 10-719 Olsztyn, Poland
}

\begin{abstract}
The topic of this article is the issue of railway track realignment. For this purpose, a computer software application was created that supports computations and generates a report needed for regulation of the trajectory of the railway. This program gives the ability to import data from measurement of the railway trajectory and then perform the calculation of the mathematical realignment. The result of this calculation is the basis for creating a project of the railway track regulation. This program was created in collaborative research project on modernization of railway lines in Poland at the request of one of the railway companies.
\end{abstract}

Keywords: railway track realignment; GIS technology; calculations automation software; railway surveying.

\section{Introduction}

Modernization of railway lines is currently the priority of Polish rail infrastructure owners. Meeting the requirements connected with high-speed rail utilization requires a number of projects whose aim is to bring up technical parameters of the existing infrastructure to the new standards. The constant utilization of tracks is connected with periodic inspections and inventory processes that help maintain railway routes on a required technical level. In case the inspection results are not satisfactory, the existing tracks need to be either realigned or upgraded [4].

Today, a continuous satellite measurements are used to recreate the position of the axis track in the global orthogonal coordinate system [3]. The aim of this article is to present a computer application which provides the interactive aid in designing projects for horizontal track axis realignment based on direct coordinate measurements. This program was created in a collaborative research project on modernization of railway lines in Poland at the request of one of the railway companies. The main objective and requirement of the ordering party was automation of the calculation process and optimization of route parameters using the orthogonal regression method. The final result of the calculations may be the development of a realignment project. The guidelines were based on Polish instruction on organization and carrying out measurements in railway surveying - D-19 [5]. It is also an attempt to adjust the computer application to the regulations and procedures present in the Polish railways. Authors of the following article allow the possibility of conducting further research on this subject. The program utilizes mathematical assumptions, which were developed for the same purposes, published and introduced at the present conference (Vilnius 2014), among others, by S.Cellmer and J.Rapiński.

\section{Application}

Leading applications that perform similar tasks are IN RAIL and MOSS. They allow projects to conducted and significantly reduced development time [1]. The ordering party requested an application which gives the possibility of influencing its internal algorithms. Possession of the source code will allow for future in-house development. For the purpose of this article, the authors will use the working name RAIL-alignment.

Among other things, RAIL-alignment allows:

- importation of text files containing point coordinates:

- axis of the track points

Corresponding author: Artur Janowski. E-mail address: artur.janowski@geodezja.pl

http://dx.doi.org/10.3846/enviro.2014.143

(C) 2014 The Authors. Published by VGTU Press. This is an open-access article distributed under the terms of the Creative Commons Attribution License, which permits unrestricted use, distribution, and reproduction in any medium, provided the original author and source are credited. 
- hypothetical collision points (technical infrastructure points that can be located in the projected gauge area)

- points of realignment signs

- calculation of values connected with the axis of the track project, particularly:

- calculation of sagittas for sagittas graph

- line estimation

- arc estimation

- calculation of via points

- calculation of points determining track routes

- calculation of points determining gauge point routes

- collision analysis of the gauge area and infrastructure elements

- measurements needed for implementing the project in the field

- preparation reports containing measurements needed for implementation - PDF file

- manipulation of both program database and graphic data

- creation of graphic layers from database points obtained from measurements and calculated elements

\subsection{Data sources used in the application}

RAIL-alignment utilizes GIS technology. The program receives data from plain text files containing data about points. The input data is simple in format, which makes it universal [nr], [x], [y], [h], [km] where:

[nr] - point number (text value);

$[\mathrm{x}],[\mathrm{y}]-\mathrm{x}, \mathrm{y}$ coordinates (actual values);

[h] - height (actual value);

$[\mathrm{km}]$ - chainage (actual value).

After importing, all data is allocated to appropriate graphic layers and corresponding database tables. The application is able to receive large data sets, including also data sets from GPS/RTK calculations.

RAIL-alignment stores data in GIS layers, which consist of database tables and linked SHP files. Such functionality was achieved thanks to MapWinGIS ActiveX Control [7], distributed under MPL 1.1 open source license, allowing for the commercial and non-commercial use. Each layer consists of three files:

1. .SHP file, which contains graphic data.

2. .DBF file, which contains descriptive data (database table).

3. .SHX file, which contains indexes for SHP records (serves as an SHP-DBF connector).

Such a format is the open standard of ESRI, widely applied in many Geographic Information Systems (GIS) [6].

\subsection{Program database}

Each project stores data in the layers which are linked to database tables (Fig. 1):

1. Points (table: point). Contains data about points obtained via measuring. Data for this table has to be imported from a text file.

2. Calculated points (table: calculate_point). Contains data obtained from calculations performed by the application.

3. Collision points (table: collision_point). Contains data about points which may be located near the gauge, e.g. infrastructure surrounding the track. Data about these points should come from the direct measurement.

4. Realignment points (table: Contains data about points representing the realignment signs.

5. Main points (table: maint_point). Contains data about mathematical determination of arc and line start/end points, which form the axis of the track trajectory.

6. Rails (table: rail). Contains data about the location of the points constituting the left and the right rail.

7. Gauge points (table: gauge_point). Contains similar data as the "Rails" table but concerning the gauge.

8. Realignment lines (table: realignment_line). This table contains data about the polygonal chain between the realignment signs. It is used to visualize the line.

9. Straight lines (table: line). Contains data about the estimated straight lines. Data is not visualized on a map.

10. Arcs (table: arc). Contains data about the estimated arcs. Data is not visualized on a map. 


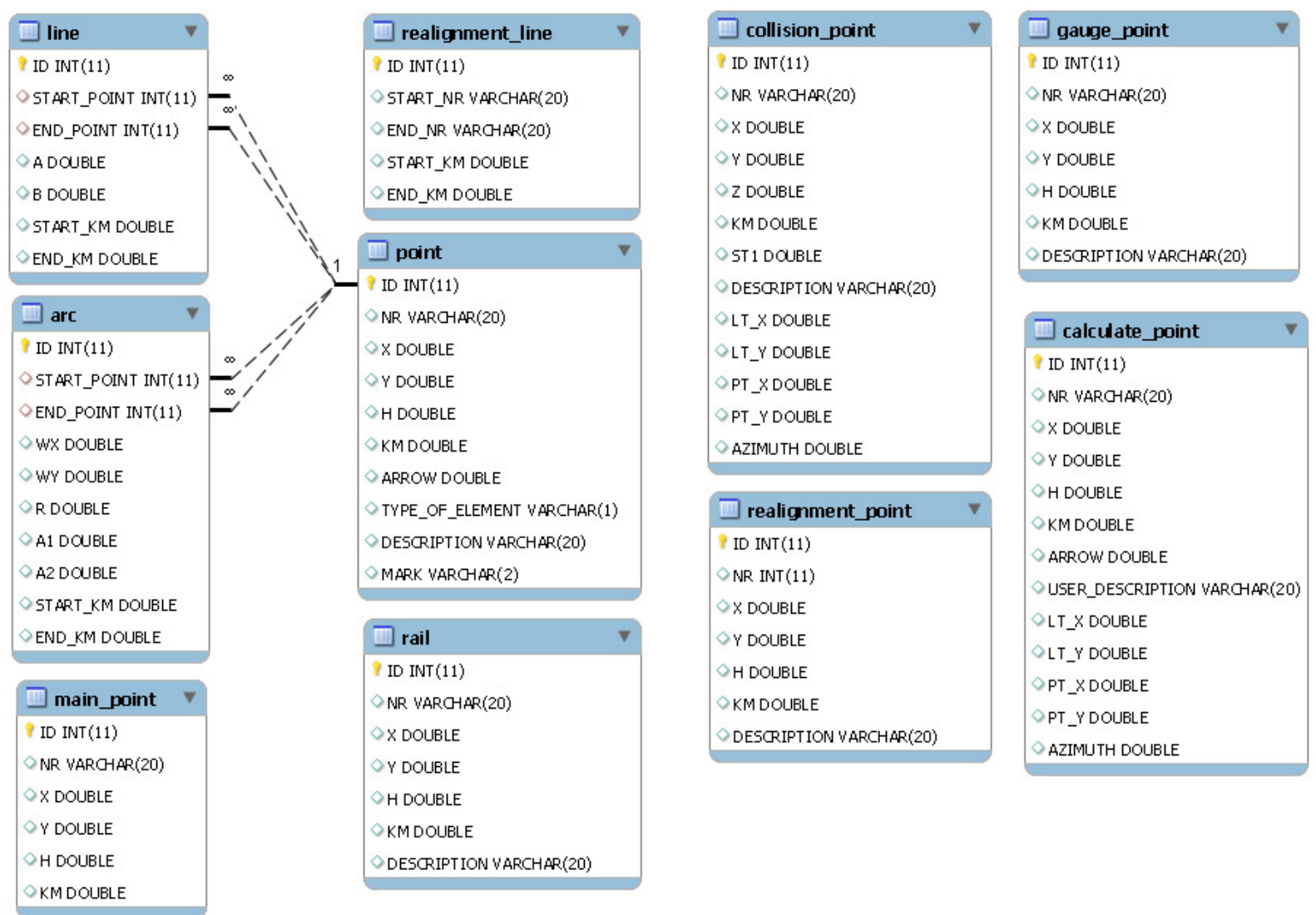

Fig. 1. The database schema

\subsection{Application interface - description}

The main window is divided into four basic sections (Fig. 2):

1. The "Database" panel. It shows the contents of a chosen database table. The currently displayed table can be switched by changing the dropdown box value located in the same panel. It is also possible to mark the point as set by clicking the "'S' Set" button, thus setting it as an invariant in the line segment calculations. What is more, it is possible to edit the DESCRIPTION field, provided that such a field exists in the table.

2. The "Selected points" panel. It presents data selected by the user on the basis of set criteria, e.g. the value range of a selected table field. The window also gives the possibility to erase individual points or mark which arc or line they belong to.

3. The map. This field contains graphic data from SHP files.

4. The sagittas graph. Identification of the railway track geometry may be based on graphical evaluation of angles, curves and sagittas [1], [2]. Presented software allows user to identify arcs and straight lines using the sagittas graph. The graph presents sagittas calculated for the currently displayed layer, if the layer contains such data. 


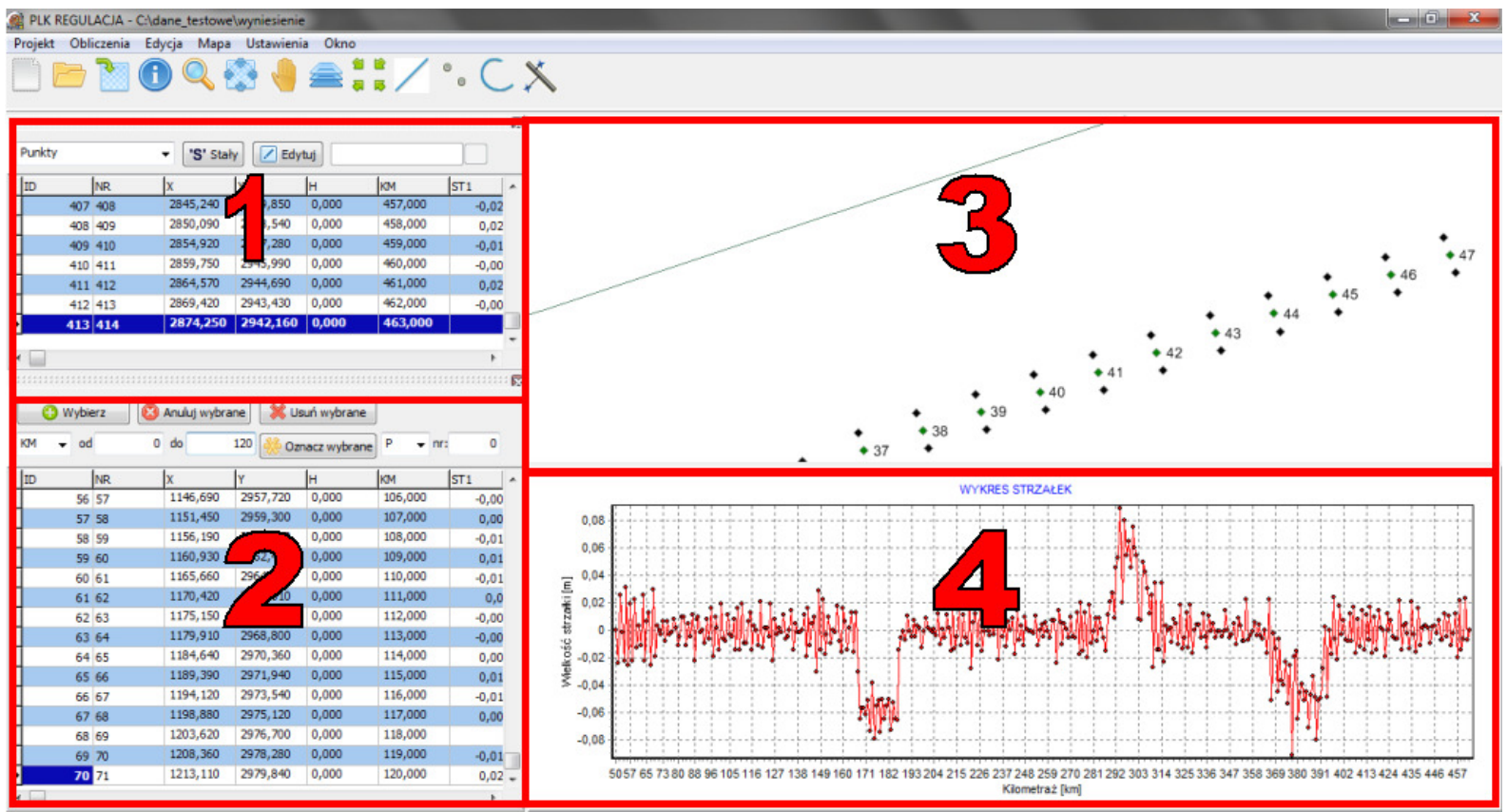

Fig. 2. Main window

Furthermore, there is a menu at the top of the window, which contains all program functions. Below users can find a toolbar with the most frequently used functions.

\subsection{Calculation process}

The calculation results are saved in the project files, which give the opportunity to read and edit them later. In order to perform the realignment project, the user may begin by starting a new empty project. Then, it is necessary to import the data, such as:

1. Data about the measurement points of the track's axis, located in the "Points" layer.

2. Data about points representing realignment signs, located on the "Realignment signs" layer.

3. Data about the points whose location can cause collisions with the gauge of the realigned track,located in the "Collision points" layer.

After importing the data, users have the possibility to change the properties of graphic layers (including turning visibility on/off and displaying labels) and get descriptive information about the indicated object (Fig. 3).

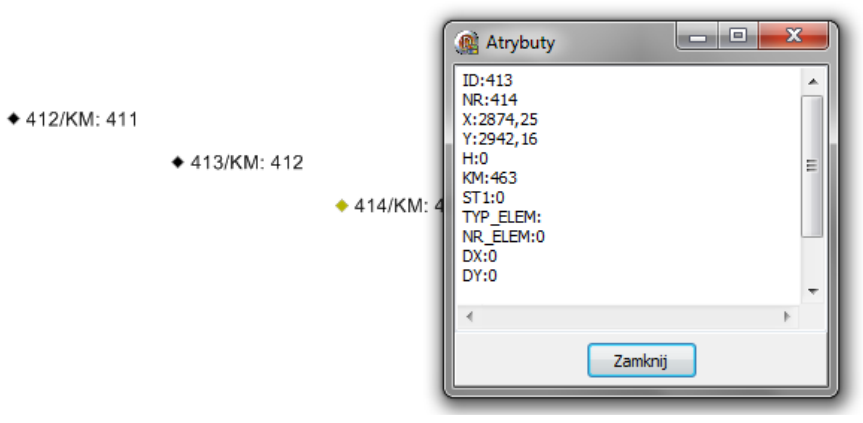

Fig. 3. Descriptive information about the indicated object

The next step after importing the data is to perform calculations. All calculation options are located in the "Calculations" (pl. Obliczenia) main menu (Fig. 4) and on the toolbar.

\begin{tabular}{|l|l|}
\hline Obliczenia Edycja Mapa Ust \\
\hline פ⿺ \\
a & Oblicz wszystkie strzałki \\
C & Proste \\
$\circ$ & Łuki \\
X & Punkty pośrednie \\
\hline & Miary do wyniesienia \\
\hline
\end{tabular}

Fig. 4. The "Calculations" main menu 
The calculations for the realignment project have to be performed in a certain order, as the following calculations use data from the preceding ones. The sequence is as follows:

1. Calculation of sagittas (pl. Strzalki).

2. Data preparation - marking lines and arcs.

3. Calculation of lines (pl. Proste).

4. Calculation of arcs (pl. Łuki).

5. Calculation of via points, rails, gauges, and the collision analysis (pl. Punkty pośrednie).

6. Calculation of measurements for implementation, report generation (pl. Miary do wyniesienia).

Issues related to each activity are discussed below.

Calculation of sagittas and data preparation. The sagittas graph is shown in the "Sagittas graph area" (pl. Wykres strzatek) of the main window. The graph is generated on the basis of numerical data from the "Points" table and allows for the axis of the track curvature analysis. The X-axis of the graph presents the arrow value expressed in [m]. The Y-axis shows the points' chainage $[\mathrm{km}]$. Sagittas values on the straight line segment oscillates around $0 \mathrm{~mm}$. Sagittas values on arcs are significantly larger (or smaller) than on straight lines, which is clearly visible on the graph. Therefore, it is necessary to determine the chainage range which includes particular arcs and lines. Next, using the Selected points' panel the user has to choose individual point ranges from the "Points" table and mark them as belonging to the arc or line (Fig. 5).

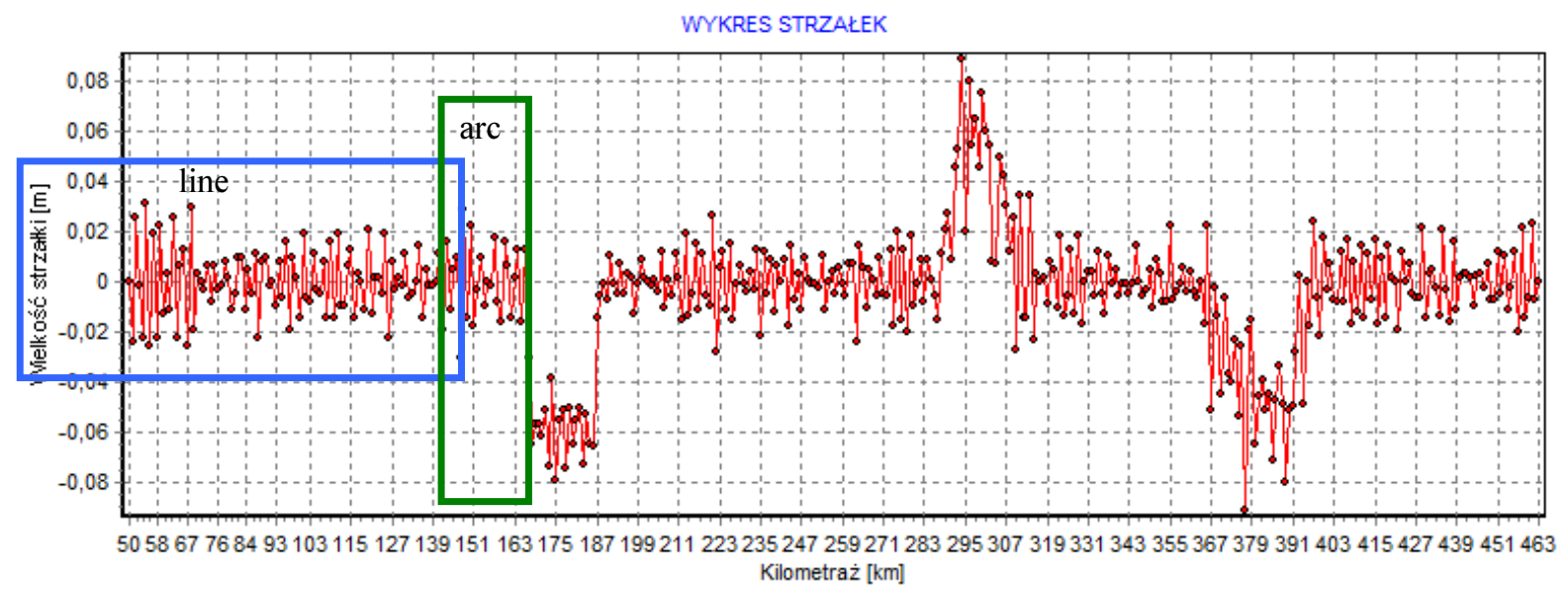

Fig. 5. Sagittas graph

When following the procedure described above, it is necessary to mark all lines and arcs in the project. When marking arcs and lines, appropriate records are added to the "Arcs" and "Straight lines" tables. They represent the marked elements and will then be used to store the results of calculations performed later. So that further calculations proceed properly, the system of arcs and lines should begin and end on straight line segments.

After marking all lines and arcs, it is necessary to start the calculation of line parameters (Fig. 6).

Calculation of line parameters. In order to calculate parameters of a line, it is necessary to input its number (according to the "Points" table) and then click the "Calculate" (pl. Oblicz) button. As a result, line parameters and point corrections from which the line is estimated will be calculated.

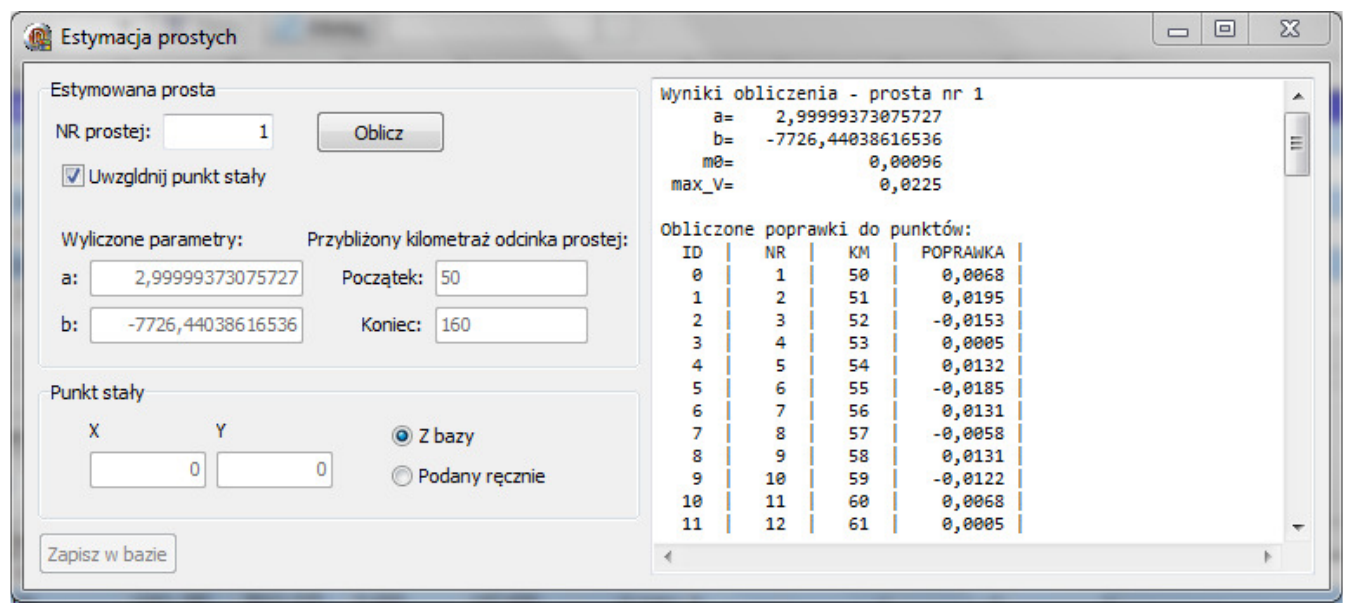

Fig. 6. Calculation of line parameters window 
It is also possible to include the set point located on a line during the calculation process. In order to do this, "Include set point" (pl. Uwzględnij punkt staty) should be selected as well as one of two options:

1. "From database" (pl. Z bazy) - means getting coordinates of a set point, which was marked on the line as set, from the "Points" table. If there is no such point in the database, choosing this option will stop the calculation process.

2. "Manual input" (pl. Podany ręcznie) - point coordinates can be input in the provided "X" and "Y" fields.

Calculation of arc parameters. Arc parameters are estimated including the condition of tangency for lines between which they are placed. In order to calculate the arc parameters (Fig. 7) it is necessary to enter the numbers (according to the "Points" table numeration) in the "Input data" option group (starting from the left):

- line before the arc;

- arc;

- line after the arc.

Then click the "Calculate" (pl. Oblicz) button. Arc parameters, maximum speed and point corrections will be calculated.

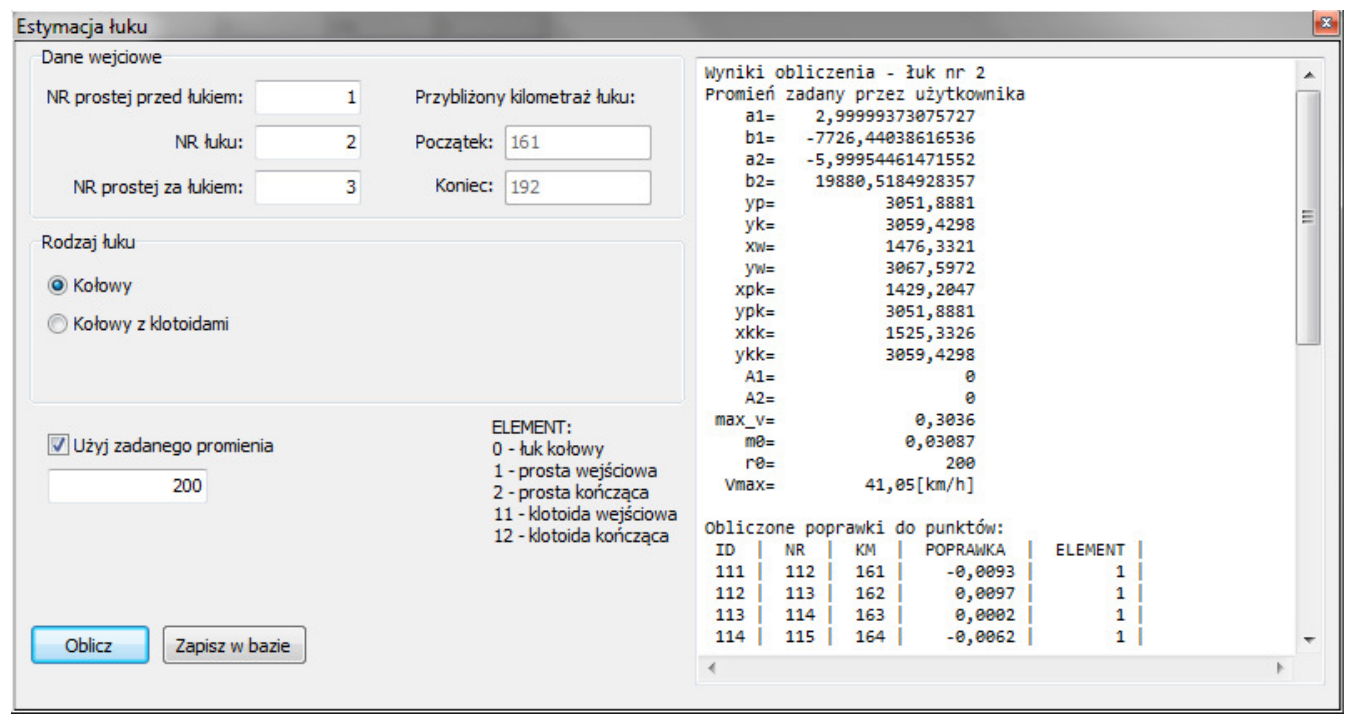

Fig. 7. Calculation of arc parameters window

It is possible to specify the arc type in the "Arc type" option group before starting the calculation:

- a circular arc (pl. Kolowy), or

- a circular arc with clothoids (pl. Kolowy z klotoidami).

There is also the possibility of calculating the arc with a set radius by selecting the "Use provided radius" (pl. Użyj zadanego promienia) and entering the wanted value.

Calculation of via points. Calculating the via points is performed for all marked elements. Thus it is advised to maintain continuity between marked arcs and lines. The calculating algorithm will start for the first point in the set of elements (according to the chainage). It should be the starting point of the first straight line. Before starting the calculation (Fig. 8) process it is necessary to establish an interval (expressed in meters) in which the points will be inserted by entering the value in the appropriate field. The calculation will start after the "Calculate via points" (pl. Oblicz punkty pośrednie) button is clicked. 


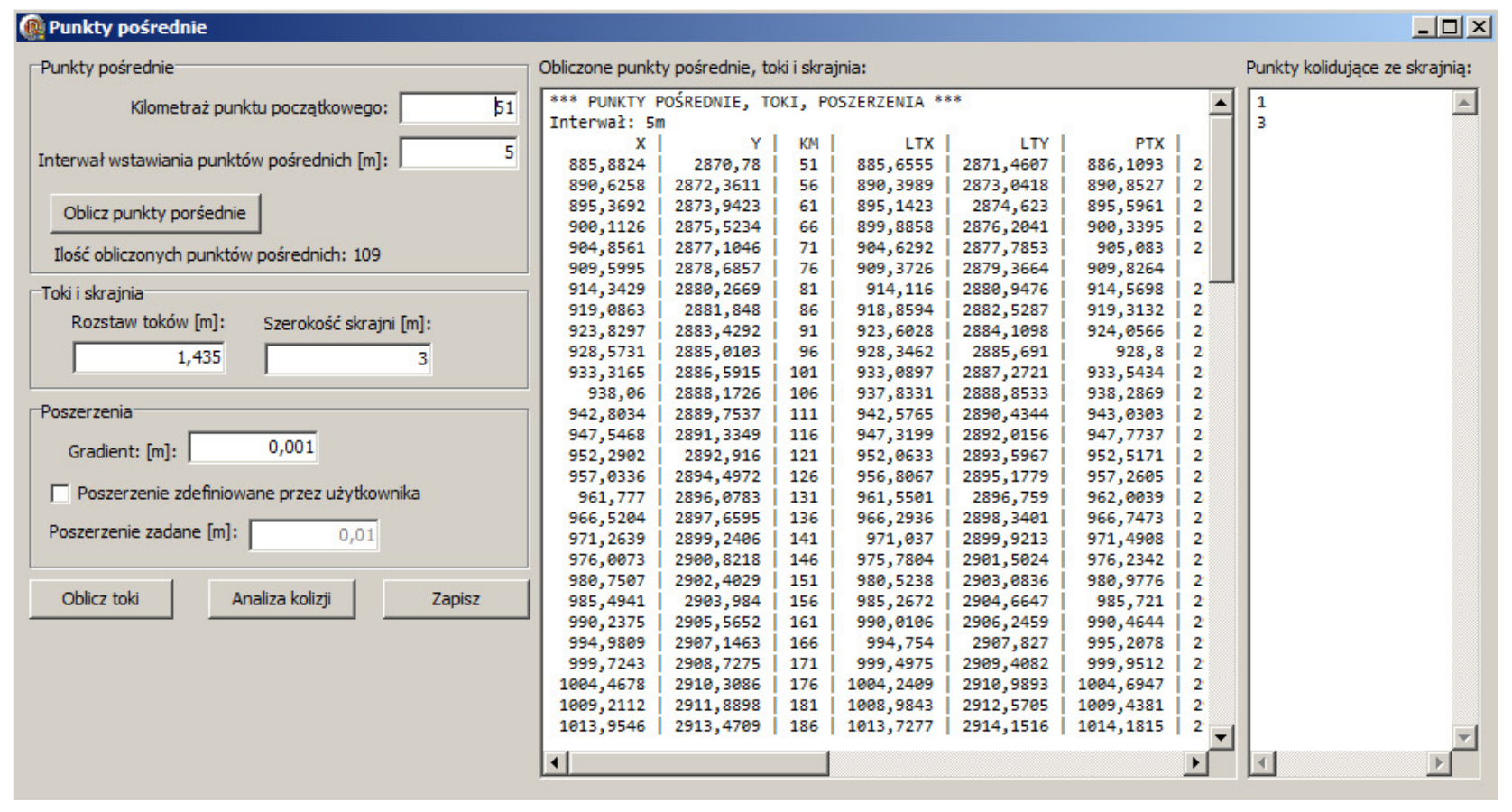

Fig. 8. Calculation of via points, rails, gauges and collision analysis

Calculation of rails and gauges. Coordinates of points determining rails and the gauge are calculated separately by clicking the "Calculate rails" (pl. Oblicz toki) button (Fig. 8). These values can also remain not calculated, depending on the needs.

The calculation of rails and gauges requires information about:

- - the track gauge (pl. rozstaw toków)

- - the gauge width (pl. szerokość skrajni)

- - the expansion gradient (pl. gradient poszerzenia)

The track expansion on arcs is calculated automatically depending on the arc radius. It is also possible to determine the expansion value by selecting "User-defined expansion" (pl. Poszerzenie zdefiniowane przez użytkownika).

Collision analysis. When points are imported into the "Collision points" layer and gauge points have been calculated, it is possible to conduct the collision analysis by clicking the "Collision analysis" (pl. Analiza kolizji) button (Fig. 8). A polygon buffer zone based on the gauge points will be created along the axis of the track. The program will perform the analysis to find which elements from the "Collision points" layer are included in the buffer zone. Found points will be marked yellow on the map, while their IDs appear in the "Points colliding with the gauge" (pl. Punkty kolidujace ze skrajnia) field.

Graphical validation. Determined via points can be checked on a graph. In order to do it, it is necessary to calculate sagittas on "Calculated points" layer. Sagittas of via points that were generated along estimated elements should take set values:

- $\quad$ on the line: sagitta $=0$;

- on the arc: sagitta $<>0$.

Below you can find the graph showing line and circular arc sagittas based on estimated points (Fig. 9).

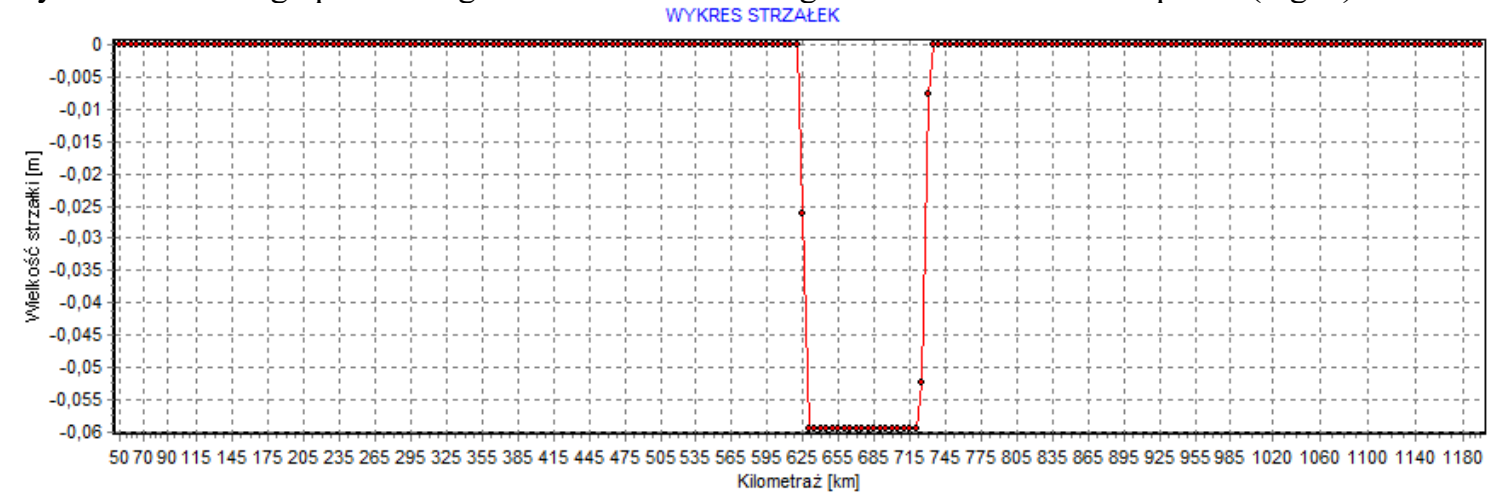

Fig. 9. Sagitta based on estimated points 
Calculation of measurements for stakeout. In order to calculate the measurements for stakeout it is necessary to import data about the position of realignment points into the "Realignment points" layer and perform all described calculations. Measurements for stakeout are generated as reports in PDF files.

\section{Data import in external programs}

Due to the data saving format, it is possible to import all calculation results into external programs in order to process them later. The data sets produced by the RAIL-alignment are saved in a popular ESRI/SHP format, which gives the possibility to open them directly in any GIS or CAD system. This data can also be opened in a graphic form (only *.shp files), or as GIS data (*.shp, *.shx, *.dbf files) which combines descriptive and graphical data.

Furthermore, database table files can be opened directly in Excel or Open Calc spreadsheets. Additionally, all calculation results are displayed by the program in a text format, which also allows to import them into spreadsheets or computer algebra systems.

\section{Summary}

The application meets all functional expectations of the ordering party. Its functionality has been proven by conducted test calculations and those based on actual values. This program requires further development to introduce further models of estimates curves. Additionally, its functionality is going to be broadened to include solutions dedicated to calculations in the vertical plane, which will provide comprehensive solution for railway track realignment.

Thanks to incorporating popular file formats, such as SHP, DBF and PRD, calculation results can easily be transferred into other $\mathrm{CAD} / \mathrm{GIS}$ systems and then be subject to further processing.

This program is characterized by its open source code (to be used within the ordering party's corporation), low hardware requirements and a user-friendly interface. It is of great significance for end users, often working on different hardware setups.

\section{References}

[1] Dobrowolski, B. 2002. Koncepcja numerycznego modelu geometrii torów w procesie napraw nawierzchni, Prace Instytutu Geodezji i Kartografii, t. XLIX(105): 77-95. Warszawa.

[2] Kedra, Z. 2006. Ustalanie wartości nominalnych w pomiarach toromierzami elektronicznymi, Problemy Kolejnictwa 143: 123-135, Warszawa.

[3] Koc, W.; Chrostowski, P. 2013. The application e_ects of continuous satellite measurements of railway lines, in Proceedings of 12th International Conference Railway Engineering 2013, 203.

[4] Geodezja inżynieryjna T. III. Praca zbiorowa 1993. Warszawa PPWK

[5] Instrukcja D-19, O organizacji i wykonywaniu pomiarów w geodezji kolejowej. Załącznik do Zarządzenia Nr 144 Zarządu PKP z dnia 23.07.2000.

[6] ESRI Shapefile Technical Description [online]. 1998. Environmental Systems Research Institute [cited 19.01.2014]. Available from internet: http://www.esri.com/library/whitepapers/pdfs/shapefile.pdf.

[7] MapWinGIS Reference Manual [online]. 2007. Mapwindow Open Source Team [cited 20.01.2014]. Available from Internet: http://mapwingis.codeplex.com/documentation. 